STUDI

FRANCESI

\section{Studi Francesi}

Rivista quadrimestrale fondata da Franco Simone

142 (XLVIII | I) | 2004

Varia - fasc. I - gannio-aprile 2004

\title{
Aa. Vv., L'Iconographie. Etudes sur les rapports entre textes et images dans l'Occident médiéval
}

\section{Maria Colombo Timelli}

\section{(2) OpenEdition}

10 Journals

\section{Édition électronique}

URL : https://journals.openedition.org/studifrancesi/40248

DOI : 10.4000/studifrancesi.40248

ISSN : 2421-5856

Éditeur

Rosenberg \& Sellier

\section{Édition imprimée}

Date de publication : 1 juillet 2004

Pagination : 155

ISSN : 0039-2944

\section{Référence électronique}

Maria Colombo Timelli, «Aa. Vv., L'/conographie. Etudes sur les rapports entre textes et images dans

I'Occident médiéval », Studi Francesi [En ligne], 142 (XLVIII | I) | 2004, mis en ligne le 30 novembre 2015, consulté le 09 septembre 2021. URL : http://journals.openedition.org/studifrancesi/40248; DOI :

https://doi.org/10.4000/studifrancesi.40248

Ce document a été généré automatiquement le 9 septembre 2021.

\section{(c)}

Studi Francesi è distribuita con Licenza Creative Commons Attribuzione - Non commerciale - Non opere derivate 4.0 Internazionale. 


\title{
Aa. Vv., L'Iconographie. Etudes sur les rapports entre textes et images dans l'occident médiéval
}

\author{
Maria Colombo Timelli
}

\section{RÉFÉRENCE}

L'Iconographie. Etudes sur les rapports entre textes et images dans l'Occident médiéval, «Cahiers du Léopard d'Or» 10, 2001, pp. 309.

1 Ce dixième «Cahier» réunit huit contributions diversement centrées sur le rapport complexe et réciproque que l'on peut reconnaître entre des textes médiévaux et les 'images' (tous supports confondus) susceptibles de les illustrer. Il peut s'agir de la relation entre la peinture murale française et les inscriptions du Dict des trois morts et des trois vifs étudiée par Marie-Laure DE CONTENSON (pp. 11-48), des glissements réciproques qui s'opèrent entre textes hagiographiques et images des bestiaires (Gaston DUCHET-SUCHAUX et G. CHEVASSU, pp. 49- 67), d'une description du monde en latin se référant à une mappemonde de la fin du XIV e siècle disparue par la suite (Jacques PAVIOT, pp. 69-97), des images des frontières de la terre habitée dans des manuscrits des $\mathrm{XI}^{\mathrm{e}}$-XIII ${ }^{\mathrm{e}}$ siècles (Danielle LECOQ, pp. 99-186), de l'iconographie relative à Saint Bœuf analysée par Dominique RIGAUX (pp. 187-203), des représentations de la crucifixion (sculptures, peintures, enluminures) avant l'an Mil (Marie-Christine SEPIÈRE, pp. 205-251), des différentes fonctions jouées par les images (bas-reliefs, verrières, sceaux, enluminures) commandées par des confréries à la fin du Moyen Age (Catherine VINCENT, pp. 253-276), des peintures de manuscrits somptueux appartenus aux plus grands seigneurs français des XIV et XV ${ }^{e}$ siècles (Christian DE MÉRINDOL, pp. 277-307). Quels que soient les textes concernés ('scientifiques' ou littéraires au sens large du terme), l'approche qui conjugue analyse de la parole et analyse de l'image, et qui permet d'appréhender le livre comme la représentation unique d'un monde, ne peut 
qu'enrichir notre connaissance de l'univers et de l'homme médiéval: c'est ce qui appelle désormais une collaboration de plus en plus stricte entre littéraires et spécialistes des représentations artistiques médiévales. 